\title{
NisB is required for the dehydration and NisC for the lanthionine formation in the post- translational modification of nisin
}

\author{
Olli Koponen, ${ }^{1}$ Marja Tolonen, ${ }^{1}$ Mingqiang Qiao, ${ }^{1}$ Gudrun Wahlström, ${ }^{2}$ \\ Jari Helin ${ }^{2}$ and Per E. J. Saris ${ }^{1}$
}

Department of Applied Chemistry and Microbiology ${ }^{1}$ and Institute of Biotechnology?2, Viikki Biocentre, University of Helsinki, Finland

\author{
Author for correspondence: Per E. J. Saris. Tel: +358 9 19159369. Fax: +358 919159322. \\ e-mail: per.saris@helsinki.fi
}

\begin{abstract}
Nisin produced by Lactococcus lactis subsp. lactis is a 34-residue antibacterial polypeptide and belongs to a group of post-translationally modified peptides, lantibiotics, with dehydrated residues and cyclic amino acids, lanthionines. These modifications are supposed to be made by enzymes encoded by lanB and lanC genes, found only in biosynthetic operons encoding lantibiotics. To analyse the extent of modification, His-tagged nisin precursors were expressed in nisB and nisC mutant strains. The His-tagged nisin precursors were purified from the cytoplasm of the cells, as lack of NisB or NisC activity impaired translocation of the nisin precursor. The purified His-tagged polypeptides were analysed with trypsin digestion followed by nisin bioassay, SDS-PAGE, $\mathbf{N}$ terminal sequencing and mass spectroscopy. According to the results, nisin precursors from the strain lacking NisB activity were totally unmodified, whereas nisin precursors from the strain lacking NisC activity, but having NisB activity, were dehydrated and devoid of normal lanthionine formation. This is the first experimental evidence showing that NisB is required for dehydration and NisC for correct lanthionine formation in nisin maturation.
\end{abstract}

Keywords: lantibiotic, dehydroalanine, dehydrobutyrine, nisin biosynthesis

\section{INTRODUCTION}

Antimicrobial peptides produced by bacteria can be classified into several groups, one of which is lantibiotics (Nes et al., 1996). These peptides are post-translationally modified, yielding mature peptides containing nontypical amino acids such as dehydroalanine, dehydrobutyrine, lanthionine and $\beta$-methyllanthionine (Sahl et al., 1995). The most prominent member of this group is nisin, produced by some Lactococcus lactis strains. Nisin is an approved food additive (E234) used in various food products (Delves-Broughton et al., 1996). The 11 genes involved in nisin biosynthesis, regulation and self-protection have been cloned and sequenced (Kuipers et al., 1993; Engelke et al., 1994; Ra et al., 1996; Immonen et al., 1998). Similar characterization work has been done for other linear lantibiotics, such as subtilin, epidermin, gallidermin and Pep5 (McAuliffe et al., 2001), of which the first three share structural similarities with nisin. Comparison of these genes with

Abbreviation: MALDI-TOF, matrix-assisted laser desorption ionization/ time-of-flight. each other and to genes of known function in addition to functional analysis identifies two genes, $\operatorname{lan} B$ and $\operatorname{lan} C$, found only in gene clusters needed for the biosynthesis of lantibiotics. These genes potentially encode the enzymes involved in the unique reactions of lantibiotic biosynthesis, i.e. the dehydration of serines and threonines of the precursor molecule, leading to dehydroalanine and dehydrobutyrine, which are essential for inhibition of spore outgrowth in the case of nisin and subtilin (Liu et al., 1993; Chan et al., 1996). Some of these modified amino acid residues are intermediate structures in the formation of lanthionine and $\beta$ methyllanthionine as a result of the addition of cysteine thiol groups to the unsaturated side groups.

Experimental evidence for the importance of $\operatorname{lan} B$ and lan $C$ genes in the dehydration of serine and threonine, and lanthionine formation has accumulated to some extent. Pep5 precursors from $p e p B$ and $p e p C$ mutant strains have been purified (Meyer et al., 1995). Analysis of these precursors showed that lack of PepB activity resulted in lack of dehydration, whereas lack of PepC activity yielded secreted precursors that had been correctly dehydrated but contained only one lanthionine 
out of three. These results showed that PepC is not required for the dehydration reaction but seems to be involved in correct lanthionine formation. Whether or not these results can be extrapolated to the biosynthesis of other lantibiotics remains to be seen. Results of Sen et al. (1999) suggested that NisB is involved in the dehydration reaction of the nisin precursor. In their experiments, overexpression of the nisB gene increased the efficiency of dehydration. Thereby, the serine at position 33 of nisin, which in engineered nisin variants [Trp30] nisin A and [Lys27, Lys31] nisin A partly escaped dehydration, could be fully dehydrated.

In this study, His-tagged nisin precursors from nisB and nis $C$ mutant strains were purified and analysed, providing evidence that $\mathrm{NisB}$ is required for the dehydration reactions and that $\mathrm{Nis} C$ is needed for correct lanthionine formation in the biosynthesis of nisin.

\section{METHODS}

Bacterial strains, plasmids, media and growth conditions. The bacterial strains and plasmids used in this study are presented in Table 1. Strains and plasmids, which need a more detailed description, are also described below. The nisin producer Lactococcus lactis N8 (Graeffe et al., 1991) was used as the host strain for making the nis $C$ mutant strain. The nonnisin producer and plasmid-free L. lactis MG1614 (Gasson et al., 1983) was used as a host strain for constructed plasmids. Micrococcus luteus A1 NCIMB 86166 (National Collection of Industrial and Marine Bacteria) was used as a nisin-sensitive indicator strain in nisin bioassays. Plasmid pLEB22 consisted of pUC6S (Viera \& Messing, 1991) with an erythromycinresistance gene, erm (Axelsson et al., 1988), functional in $L$. lactis. Plasmid pKTH1980 (Graeffe et al., 1991) served as template for amplifying the nis $Z$ gene. L. lactis expression vectors pLEB124 (Qiao et al., 1995) and pLEB384 (Qiao et al., 1996) were used as vectors for the construction of His-tagged prenisin production constructs. L. lactis cells were grown at $30{ }^{\circ} \mathrm{C}$ without shaking in M17 (Terzaghi \& Sandine, 1975) supplemented with $0.5 \%(\mathrm{w} / \mathrm{v})$ glucose and $0.5 \%$ sucrose (M17GS). Escherichia coli cells were grown at $37^{\circ} \mathrm{C}$ with shaking in Luria broth. When needed, media were supplemented with antibiotics in the following concentrations: $30 \mu \mathrm{g}$ ampicillin $\mathrm{ml}^{-1}, 200 \mu \mathrm{g}$ erythromycin $\mathrm{ml}^{-1}$ (E. coli), $5 \mu \mathrm{g}$ erythromycin $\mathrm{ml}^{-1}$ (L. lactis) and $10 \mu \mathrm{g}$ chloramphenicol $\mathrm{ml}^{-1}$.

DNA manipulations. Plasmids were isolated by alkaline lysis followed by further purification using the Magic Miniprep kit (Promega). Chromosomal DNA was isolated by the method of Marmur (1961). Established protocols were followed for molecular biology techniques (Maniatis et al., 1982). L. lactis

Table 1. Strains and plasmids used in this study

\begin{tabular}{|c|c|c|}
\hline Strain or plasmid & Relevant properties & Reference \\
\hline \multicolumn{3}{|l|}{ Strains } \\
\hline E. coli $\mathrm{DH} 5 \alpha$ & Host strain for plasmid constructions & Hanahan (1983) \\
\hline M. luteus A1 NCIMB 86166 & Nisin-sensitive indicator strain & $\begin{array}{l}\text { National Collection of Industrial } \\
\text { and Marine Bacteria }\end{array}$ \\
\hline \multicolumn{3}{|l|}{ L. lactis } \\
\hline N8 & Nisin Z producer & Graeffe et al. (1991) \\
\hline M61614 & No plasmids, no nisin genes & Gasson et al. (1989) \\
\hline NZ9800 & nis $A$ mutant & Kuipers et al. (1993) \\
\hline LAC53 & nisB mutant & Qiao et al. (1996) \\
\hline LAC71 & nisP mutant & Qiao et al. (1996) \\
\hline LAC104 & nis $C$ mutant & This study \\
\hline LAC166 & LAC104 + pLEB563 & This study \\
\hline LAC208 & NZ9800 with pLEB561 & This study \\
\hline LAC214 & LAC53 + pLEB563 & This study \\
\hline LAC212 & LAC104 + pLEB563 & This study \\
\hline \multicolumn{3}{|l|}{ Plasmids } \\
\hline $\mathrm{pNZ8010nisB}$ & $\mathrm{P}_{n i s A}$ nis $B$, the nis $B$ complementation plasmid & Kuipers et al. (1993) \\
\hline pLEB22 & erm & Per Saris, Helsinki \\
\hline pLEB36 & 'nisTCIP' & Immonen et al. (1995) \\
\hline pK601-3 & His-tag & Kari Keinänen, Helsinki \\
\hline pKTH1980 & nis $Z$ & Graeffe et al. (1991) \\
\hline pCRII & $\mathrm{T} / \mathrm{A}$ cloning vector & Invitrogen \\
\hline pLEB124 & L. lactis expression vector with $\mathrm{P}_{45}$ promoter & Qiao et al. (1995) \\
\hline pLEB384 & pLEB124 + cat & Qiao et al. (1996) \\
\hline pTClux $\mathrm{Hb}$ & Vector used for the nis $C$ complementation plasmid & Jacob et al. (1995) \\
\hline pLEB406 & erm, 'nisC', integration plasmid & This study \\
\hline pLEB507 & $\mathrm{P}_{45}+$ nis $C$, the nis $C$ complementation plasmid & This study \\
\hline pLEB544 & His-tagged nis $Z$ & This study \\
\hline pLEB561 & pLEB124 + His-tagged nisZ & This study \\
\hline pLEB563 & pLEB $384+$ His-tagged nis $Z$ & This study \\
\hline
\end{tabular}




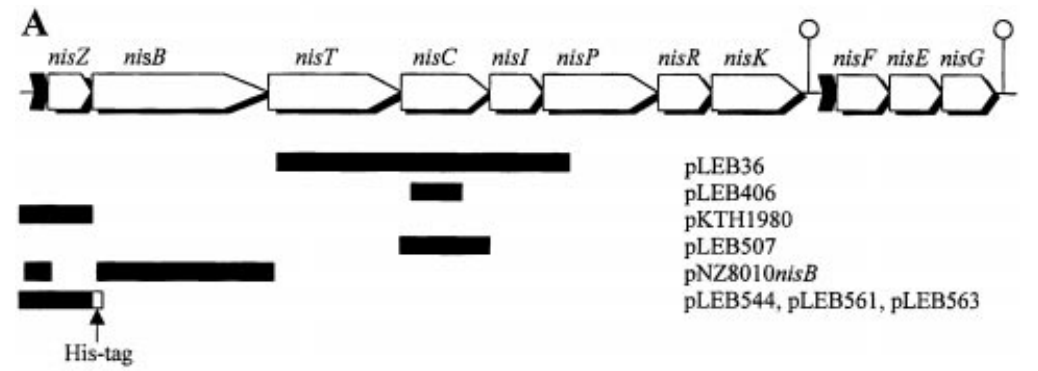

B

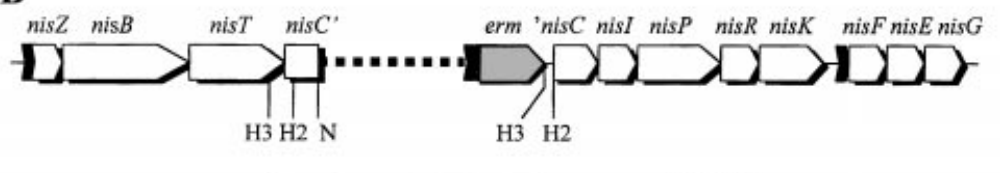

Fig. 1. Schematic presentation of the nisin operons of L. lactis N8 and LAC104 (the nisC mutant) and cloned nisin sequences. (A) The nisin operons of N8 (Immonen et al., 1995; Immonen \& Saris, 1998) and nisin regions used. The nisin-inducible promoters are shown in black and the hairpin loops represent the Rho-independent transcription stop signals. The constitutive nisR promoter is not shown. (B) The nisin operons of LAC104 with pLEB406 integrated into the nis $\mathrm{C}$ gene. The plasmid sequence is shown as dots and promoters, except nisR, are shown as black arrows. Only relevant restriction enzymes sites are shown. H2, Hincll; H3, HindIII; N, Ncol. cells were transformed by electroporation (Holo \& Nes, 1989). DNA was cleaved, ligated and amplified according to the conditions recommended by the supplier of enzymes used (Promega). Oligonucleotide primers used in amplification of the nis Z gene were O423 (Graeffe et al., 1991) and NIS123 (5'-GCTCTAGATTTGCTTACGTGAATACTACA-3'). Primers used in amplification of the nis $C$ gene were $\mathrm{N} 17\left(5^{\prime}\right.$ GAACTTTATTATTCAGAGC-3') and NIS41 (5'-TCAGTTAATCATTTCCTCTTCCCTCCTTTCA-3'). PCR was performed in a Perkin Elmer Cetus DNA thermal cycler using Taq polymerase (Promega).

Nisin bioassay. Antibacterial activity of nisin was determined as growth inhibition zones on M17GS agarose plates inoculated with $M$. luteus, a nisin-sensitive indicator strain. On the top of the agar surface, $3 \mu$ lof the sample or a streak of the bacterium to be tested was applied. The plates were read after growth of approximately $16 \mathrm{~h}$ at $37^{\circ} \mathrm{C}$. As positive control, a dilution series $\left(0-10 \mu \mathrm{g} \mathrm{ml}^{-1}\right)$ of nisin (Sigma) was used. Trypsin treatment of the isolated nisin precursor prior to nisin bioassay was done as described previously (Qiao et al., 1996).

Western analysis. Proteins were separated using $20 \%$ SDSPAGE, and transferred to an Immobilin filter. The filter with the proteins was treated according to the instructions of the Protoblot (Stratagene) immunodetection kit. The specific antiserum used to detect the His-tag was the mouse IgG1 isotype RGS-His antibody (Qiagen).

Inactivation of the nisC gene. First, a nis $C$ inactivation plasmid was constructed. The internal fragment (HincII$\mathrm{NcoI}$ ) of the nis C gene in plasmid pLEB36 was cloned into pLEB22, a pUC6S derivative not able to replicate in Grampositive bacteria but containing a functional selection marker, erm, for L. lactis. This constructed plasmid pLEB406 was transformed into the nisin producer L. lactis N8 with erythromycin selection. Erythromycin-resistant transformants potentially contained plasmid pLEB406 integrated into the chromosome. If integration had occurred by recombination in the nis $C$ sequence, the transformants would have two kinds of mutated nis $C$ genes, one with a deletion in the $5^{\prime}$ part (nonfunctional due to lack of RBS, initiation codon and the first 33 amino acids) and the other with a deletion in the $3^{\prime}$ part (potentially non-functional due to deletion of the 88 amino acids from the C-terminus). Integration of plasmid pLEB406 into the nis $C$ gene would place the erm gene, which does not contain a transcriptional terminator, in front of the nisIPRK genes, ensuring transcription of these genes from the constitutive $\mathrm{erm}$ promoter (Fig. 1).

Purification of the His-tagged prenisin. L. lactis strains LAC214 and 212 were first grown in $21 \mathrm{M} 17 \mathrm{G}$ until $\mathrm{OD}_{600}$ reached $0 \cdot 2$, followed by addition of nisin to a final concentration of $25 \mathrm{ng} \mathrm{ml}^{-1}$ to induce the nisin operons and the production of the His-tagged nisin precursor. Cultivation was then continued for $4 \mathrm{~h}$ and the cells were collected by centrifugation. Cells containing the His-tagged prenisin were digested with $4 \mathrm{mg}$ lysozyme $\mathrm{ml}^{-1}$ in phosphate buffer, $\mathrm{pH} 7 \cdot 4$, for $1 \mathrm{~h}$ at $37^{\circ} \mathrm{C}$, followed by freezing and sonication to disrupt the cells. The unbroken cells and cell debris was removed by centrifugation $(30000 \mathrm{~g}, 30 \mathrm{~min})$. The supernatant was filtered using a MillexHV $0.45 \mu \mathrm{m}$ filter. Imidazole was added to the supernatant to a final concentration of $140 \mathrm{mM}$ and loaded to a $5 \mathrm{ml}$ HisTrap column (Pharmacia). Washing and elution of the HisTrap column was done according to the instructions of the supplier. After a lyophilization step and resuspension in water (adjusted with $\mathrm{HCl}$ to $\mathrm{pH} 2 \cdot 5$ ), samples of the fractions were analysed using 20\% SDS-PAGE. The fractions containing the highest amount of the expected product (expected migration according to a size of approximately $6.9 \mathrm{kDa}$ ) were further purified using a reverse-phase column DeltaPak C4 $(3.9 \mathrm{~mm}, 150 \mathrm{~mm}$ and $5 \mu \mathrm{m}$ ) with the HP1090 Liquid Chromatograph model 1040A (Hewlett Packard). A 3-60\% gradient of acetonitrile for $20 \mathrm{~min}$ was used for elution.

$\mathrm{N}$-terminal amino acid sequencing and mass spectrometry. Confirmation of the identity of the putative His-tagged prenisin from the last purification step was done by $\mathrm{N}$ terminal sequence analysis in a gas/pulsed liquid sequencer (Kalkkinen \& Tilgman, 1988). The mass of the His-tagged nisin precursor was analysed using matrix-assisted laser desorption ionization time-of-flight (MALDI-TOF) MS on a Biflex time of flight instrument (Bruker-Franzen Analytik) equipped with a laser operating at $337 \mathrm{~nm}$ as described previously (Saarinen et al., 1999).

\section{RESULTS}

\section{Inactivation of the nis $C$ gene}

The aim of this study was to analyse the role of NisB and $\mathrm{NisC}$ in the modification of nisin by purification and analysis of modification intermediates from strains 


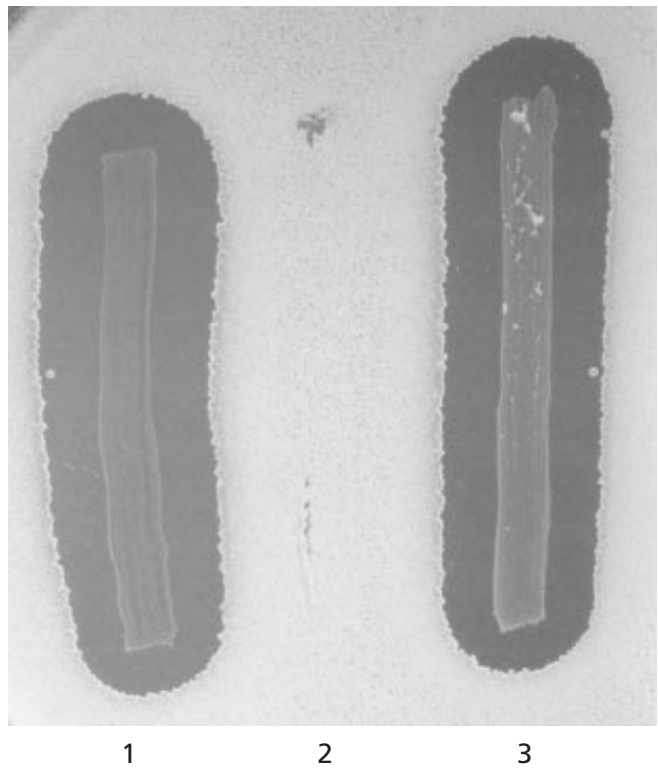

Fig. 2. Complementation of the nis $\mathrm{C}$ mutation. Bacterial streaks 1 (L. lactis N8, wild-type nisin producer), 2 (L. lactis LAC104, nisC mutant) and 3 (L. lactis LAC104, containing plasmid pLEB507 with an intact nis ( gene) on agarose with a lawn of $M$. luteus. The dark zone around streaks 1 and 3 indicate inhibition of $M$. luteus by nisin produced by the bacteria in the streaks. The experiment was repeated three times with similar results.

lacking NisB or NisC activity. Therefore, nisB and nis $C$ mutant strains having the other nisin genes transcribed were needed. We have previously constructed a nisB mutant strain, LAC53, in which the downstream genes (nisTCIPRK) are transcribed from the promoter of the erm gene located downstream of the nisB mutation (Qiao et al., 1996). This strain could be used for analysis of NisB function. A nis $C$ mutant strain had to be constructed because previously described nis $C$ mutants (Siegers et al., 1996; Ra et al., 1999) were either polar (Ra et al., 1999) or no data regarding the polar effect on the nisIPRK genes downstream of the nis $C$ gene were available. The putative nisC mutants obtained by transformation of plasmid pLEB406 into L. lactis N8 were tested for nisin production and none of the transformants produced nisin. This indicated that plasmid pLEB406 had integrated into the nis $C$ gene because nis $C$ mutants do not produce nisin (Siegers et al., 1996; Ra et al., 1999). To confirm the site of integration, one transformant, named LAC104, was analysed further. The integrated plasmid pLEB406 with flanking DNA was excised with HindIII out of the isolated chromosomal DNA of LAC104 (Fig. 1B), circularized with ligase and transformed into E. coli where this plasmid, named pLEB407, can replicate. Analysis of the flanking DNA of pLEB407 by restriction enzymes verified that $\mathrm{pLEB} 406$ had integrated into the nis $C$ gene in the LAC104 strain as the flanking DNA upstream of the HincII site contained the $5^{\prime}$ sequence of the nis $C$ gene not present in pLEB406 (results not shown). A nisCexpressing plasmid was constructed (pLEB507) and transformed into the LAC104 strain for complementation studies, yielding strain LAC166. Plasmid pLEB507 was constructed by cloning a nis $C$ gene containing PCR fragment, generated with primers NIS17 and NIS41 using L. lactis $\mathrm{N} 8$ chromosomal DNA as template, into plasmid pTCluxHb with HindIII/BamHI ends. Strain LAC166 harbouring this plasmid gained the capability to produce nisin (Fig. 2). This showed that the intact nis $\mathrm{C}$ gene in the pLEB507 plasmid could complement the nis $C$ mutation and that the other genes in the nisin operons were functional and expressed to levels needed for nisin production. Therefore, the LAC104 strain fulfilled all the requirements for the planned analysis. The nisB mutant strain LAC53 has been previously constructed (Qiao et al., 1996) and the nisB gene complemented with plasmid pNZ8010nisB (Kuipers et al., 1993) (results not shown). Therefore, also this strain fulfilled all the requirements for the planned analysis.

\section{Construction and evaluation of the functionality of a His-tagged nisin}

For analysis of nisin precursors expressed in the NisB and NisC mutant strains, these precursors had to be purified. A His-tag coding sequence was added to the nis $Z$ gene to aid the purification step. For this construction the nis $Z$ gene was amplified using PCR with primers O423 and NIS123 and plasmid pKTH1980 as template. NIS123 was designed such that an XbaI site was created before the stop codon of the nis $Z$ gene. The amplified fragment was first cloned into the pCRII T/A vector and from there as an EcoRI-XbaI fragment into plasmid pK601-3, resulting in plasmid pLEB544 containing the nis $Z$ gene with a His-tag coding region inframe fused to the $3^{\prime}$ end of the nis $Z$ gene. To be able to express the His-tagged nisin precursor in L. lactis, the gene was removed from pLEB544 as a BamHI fragment and cloned into the expression vectors pLEB124 and pLEB384, resulting in pLEB561 and pLEB563. The only difference between these two plasmids is that the latter also contains a chloramphenicol marker selectable in $L$. lactis. Plasmid pLEB561 was transformed into the nis A mutant strain L. lactis NZ9800 (Kuipers et al., 1993), resulting in LAC208. The NZ9800 host strain does not produce nisin but can be complemented by an intact nisZ gene (Kuipers et al., 1993), a natural variant of the nis A gene with only one nucleotide difference (Graeffe et al., 1991; Mulders et al., 1991). If the His-tagged nisin precursor encoded by the pLEB561 plasmid were a functional substrate for the nisin maturation machinery, then LAC208 should be able to produce active nisin. Without nisin induction the cells of LAC208 did not produce nisin, but induction with $25 \mathrm{ng}$ nisin $\mathrm{ml}^{-1}$ resulted in secretion of active nisin (Fig. 3). This result showed that the His-tagged nisin precursor is a functional substrate for the nisin modification enzymes and transport protein, but not a functional inducer of the positively autoregulated nisin operons (Kuipers et al., 1995; Qiao et al., 1996; Ra et al., 1996). Therefore, plasmid pLEB563, identical to pLEB561 except for the chloramphenicol-resistance marker, was transformed 


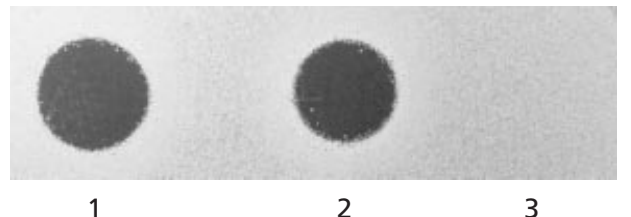

Fig. 3. Verification of the functionality of His-tagged prenisin for the nisin modification machinery of L. lactis NZ9800. Spots: 1 , growth supernatant of $L$. lactis N8, wild-type nisin producer; 2, nisin (25 $\left.\mathrm{ng} \mathrm{ml}^{-1}\right)$-induced growth supernatant of L. lactis LAC208, the nisA mutant NZ9800 containing plasmid pLEB561 with the gene encoding His-tagged nisin; 3, growth supernatant of L. lactis LAC208 without nisin induction. The dark spots indicate inhibition of $M$. luteus on the agar surface by nisin produced into the growth supernatants. The MIC value for $M$. luteus in this assay is approximately $50 \mathrm{ng} \mathrm{ml}^{-1}$. The experiment was repeated three times with the same result.

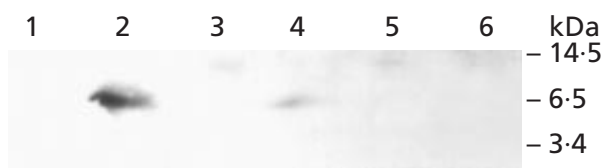

Fig. 4. Western analysis of proteins produced by $L$. lactis LAC214 and 212 using a His-tag-specific antiserum. Lanes: 1, cells of LAC214; 2 , cells of nisin-induced LAC214; 3 , cells of LAC212; 4, cells of nisin-induced LAC212; 5, growth supernatant of nisin-induced LAC214 cells; 6, growth supernatant of nisin-induced LAC212 cells. The experiment was repeated three times with similar results.

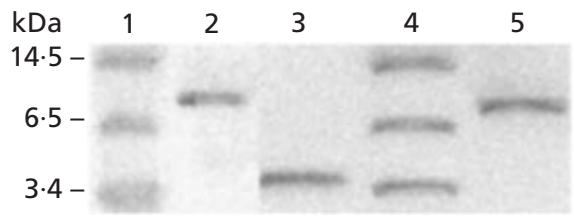

Fig. 5. SDS-PAGE analysis of His-tagged prenisin purified from the nis $B$ and nisC mutants by His-Trap purification. Lanes: 1, molecular mass marker; 2 , His-tagged prenisin isolated from $L$. lactis LAC214; 3, nisin; 4, molecular mass marker; 5, His-tagged prenisin isolated from the LAC212 strain. The experiment was repeated three times with the same result.

into the nis $B$ and nis $C$ mutant strains LAC53 and LAC104, resulting in LAC214 and LAC212, in order to produce partially modified nisin for analysis of the function of the NisB and NisC enzymes. Growing the LAC214 and LAC212 cells in M17GS supplemented with $25 \mathrm{ng}$ nisin $\mathrm{ml}^{-1}$ induced the expression of Histagged nisin precursor. No nisin activity was observed in the growth media or cells of the LAC214 and LAC212 strains, whereas nisin-induced polypeptides were observable from cells using Western analysis with a Histag-specific antiserum (Fig. 4). These polypeptides were purified and analysed by N-terminal amino acid sequen-

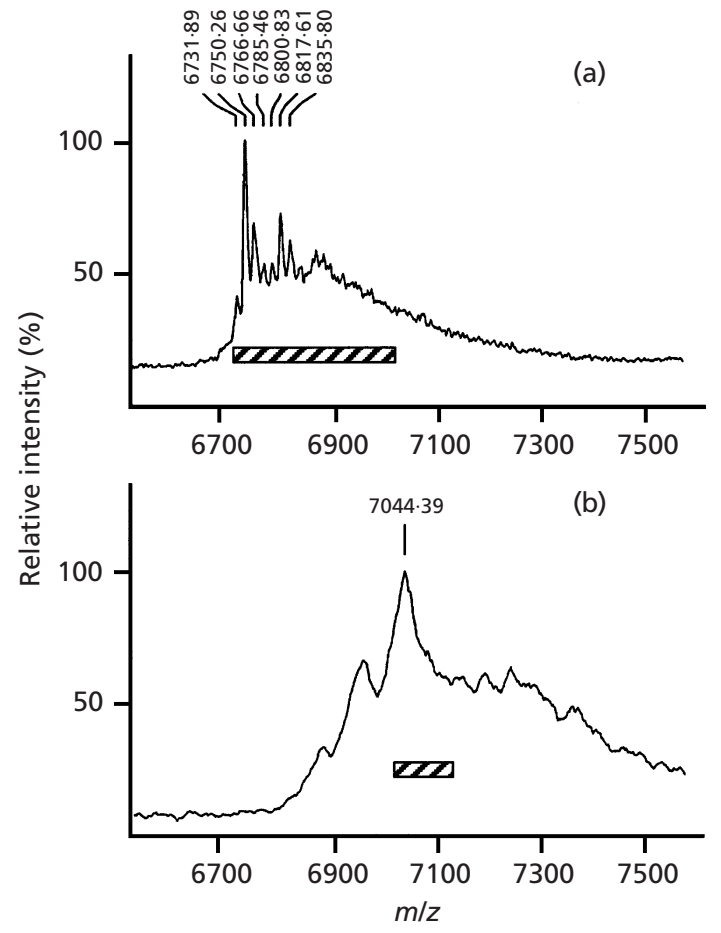

Fig. 6. Mass spectrometry analysis of His-tagged prenisin from L. lactis LAC214 and LAC212 by MALDI-TOF MS. (a) His-tagged prenisin from LAC212 (NisB is functional, but not NisC); $100 \%$ corresponds to 2750 absolute intensity. (b) His-tagged prenisin from LAC212 (NisC is functional but not NisB); $100 \%$ corresponds to 1250 absolute intensity. The relevant areas are indicated by bars, representing in (a) the expected size distribution (6736-7006 $\mathrm{Da}$, all potential residues dehydrated to no dehydration) of differently dehydrated His-tagged nisin precursors. The bar in (b) represents the expected size distribution (7006-7120 Da) of the unmodified His-tagged nisin precursor and different salt adducts thereof.

cing, SDS-PAGE and mass spectrometry analysis (Figs 5 and 6). The result of the SDS-PAGE (Fig. 5) showed that the purified putative His-tagged nisin precursor migrated as a polypeptide of approximately $6.9 \mathrm{kDa}$, indicating that the nisin leader had remained uncleaved. The Nterminal sequencing of the purified His-tagged nisin precursor verified that the purified polypeptide was the His-tagged nisin precursor with the N-terminal leader and that no modified amino acid residues were present in the leader (results not shown). The C-terminus was likely to be intact as the polypeptide could be purified using the HisTrap column and detected using Western analysis with His-tag-specific antiserum. The result of the mass spectrometry analysis is shown in Fig. 6.

The major signal in the MALDI analysis of the Histagged nisin precursor isolated from the LAC214 strain was $7044 \mathrm{Da}$, which possibly represents disodium $(+44 \mathrm{Da})$ and potassium $(+38 \mathrm{Da})$ adducts of the Histagged nisin precursor (expected mass $7006 \mathrm{Da}$ ). The mass $(6732 \mathrm{Da})$ of the polypeptides in the peak representing the lightest polypeptides purified from the 
LAC212 strain corresponded to the mass $(6736 \mathrm{Da})$ of a His-tagged nisin precursor with serine and threonine residues dehydrated similarly as in wild-type nisin. Polypeptides with slightly larger mass were also detected with mass differences (mean $17 \cdot 3 \mathrm{Da}$ ) close to the mass of water. The purified nisin precursor isolated from LAC212 could potentially contain all lanthionines typical for active nisin. Such precursors would be activated if the leader were digested with trypsin (van der Meer et al., 1993). Therefore, the isolated nisin precursor $(1 \mu \mathrm{g})$ and, as a control growth supernatant of LAC71, a nisP mutant strain secreting nisin precursors that can be activated with trypsin (Qiao et al., 1996), were treated with trypsin. Nisin activity was observable only in the control sample.

\section{DISCUSSION}

To study the function of the putative nisin-modifying enzymes NisB and NisC, several approaches are evident. The purification of LanB and LanC enzymes for enzymic studies has not been successful (Kupke \& Götz, 1996), but isolation and analysis of Pep5 lantibiotic precursors from $p e p B$ and $p e p C$ mutant strains has been successful (Meyer et al., 1995). In this study a similar approach was used to experimentally verify the putative functions of $\mathrm{NisB}$ and NisC, e.g. dehydration and catalysis of lanthionine formation. We have previously constructed a nisB mutant strain having all other nisin genes intact and transcribed (Qiao et al., 1996). A similar nisC mutant strain has not been available. Therefore, a nis $C$ mutant strain with all other nisin genes functional was constructed. Second, purification of nisin precursors expressed in nisB and nis $C$ mutant cells had to be made easy. For this purpose a His-tag was added to the $\mathrm{C}$ terminus of the nisin precursor. The functionality of this fusion protein for the nisin biosynthetic machinery had to be ensured. The results of production of this fusion protein in the nisA mutant strain showed that the Histagged nisin precursor is a functional substrate for the $\mathrm{NisB}$ and NisC enzymes, the NisT transporter and the NisP protease, otherwise active nisin could not have been detected in the growth medium after nisin induction. This also showed that the His-tag did not impair the activity of nisin.

It is known that all lanthionines are needed for nisin activity and if the leader is not cleaved by NisP, the fully modified nisin precursor still containing the N-terminal leader is inactive (van der Meer et al., 1993; Qiao et al., 1995). Interestingly, the His-tag seemed to impair the inductive capacity of nisin as no active His-tagged nisin could be produced unless cells were induced with intact nisin. Nisin-induced expression of the His-tagged nisin precursor in the LAC214 and LAC212 strains did not yield any active nisin inside or outside the cells, as expected. Western analysis with the His-tag-specific antiserum showed that if NisB and NisC do not modify the nisin precursor, the precursor could not be transported. Therefore, it is unlikely that the nisin leader could be used for directing proteins other than fully modified nisin or structurally very similar polypeptides out of the cells.

The mass spectrometry analysis, SDS-PAGE and Nterminal amino acid analysis of the His-tagged nisin precursors purified from the LAC214 and LAC212 strains showed that the N-terminal leader was not digested from the nisin precursor inside the cell. This indicates that the nisin precursor is protected from intracellular proteases as long as it is not completely modified, because in a nis $T$ mutant strain, where transport of the modified nisin was blocked, the leader was digested and active nisin could be isolated from inside the cells (Qiao \& Saris, 1996).

For every dehydration reaction the mass of the nisin precursor decreases by $18 \mathrm{Da}$. Therefore, mass spectrometry can be used to distinguish between a nisin precursor that is not dehydrated and one that is. The mass analysis of the His-tagged nisin precursor from the LAC214 strain (NisC functional but no NisB activity due to the mutation) showed that the mass corresponded to a His-tagged nisin precursor with none of the serine and threonine residues dehydrated. This shows that $\mathrm{NisB}$ is needed for the dehydration reaction to occur. The isolated nisin precursor was potentially a salt adduct in the MALDI analysis, explaining the difference in the expected $(7006 \mathrm{Da})$ versus the observed $(7044 \mathrm{Da})$ size. The nisin precursor has three negatively charged aspartate residues and can thereby attract one, two or three positively charged ions. The broadness of the mass peak (Fig. 6b) could be a result of a mixture of nisin precursors with different levels of either potassium or sodium, or mixtures thereof. The size range of the broad peak (approx. 7000-7120 Da) could include the plain nisin precursor $(7006 \mathrm{Da})$, all of the intermediate forms and the heaviest one consisting of the nisin precursor salt with three potassium ions $(7120 \mathrm{Da})$. The same analysis using the nisin precursor purified from the LAC212 strain (NisB functional but no NisC activity due to the mutation) showed that the His-tagged nisin precursor was not as heavy as when isolated from the LAC214 strain. The lightest mass peak corresponded to a His-tagged nisin precursor with serines and threonines dehydrated to an extent that occurs in wild-type nisin. The majority of the peptides had potentially fewer dehydrated residues, as indicated by the larger mass with differences close to $18 \mathrm{Da}$, the mass of water, which is removed by every dehydration reaction. This result clearly indicated that NisB seems to be responsible for the dehydration reaction and that NisB does not need $\mathrm{NisC}$ for the dehydration reaction. According to the results, NisB was not able to efficiently dehydrate all the serine and threonine residues as the majority of the nisin precursors were only partly dehydrated. The structural gene of the His-tagged nisin was located on a multicopy plasmid in the LAC214 strain, resulting in potentially too high levels of nisin precursor for the NisB enzyme to dehydrate all the potential sites. Another explanation for the partial dehydration is that lack of $\mathrm{NisC}$ has an effect on the activity of the NisB enzyme, which is known to form a complex with NisC and NisT (Siegers 
et al., 1996). Clearly, the observed inefficient dehydration by the NisB enzyme does not hinder the function of the nisin biosynthetic machinery as active His-tagged nisin could be secreted by the nisA mutant strain containing plasmid pLEB561 (Fig. 2). The nisin precursors isolated from strain LAC214 were not in the form of a salt adduct in the mass spectrometry analysis. This could be a reflection of the lower level of production of this precursor compared to precursor production of LAC212 cells, resulting in potential differences in salt concentration of the samples subjected to mass analysis. Another possibility is that dehydration of the nisin precursor results in a conformational change that makes the residues involved in adduct formation less available for salt formation to occur. By mass spectrometry analysis one cannot judge if any of the potentially dehydrated residues have reacted with cysteine to form lanthionine. However, if all lanthionines were formed, then cleavage of the leader should yield active nisin. We could not find any nisin activity after a trypsin treatment of the nisin precursor isolated from the LAC212 strain. Therefore, NisC is needed for correct lanthionine formation.

\section{ACKNOWLEDGEMENTS}

This work, project number 177321, was financed by the Academy of Finland.

\section{REFERENCES}

Axelsson, L. T., Ahrne, S. E. J., Andersson, M. C. \& Ståhl, S. R. (1988). Identification and cloning of a plasmid-encoded erythromycin resistance determinant from Lactobacillus reuteri. Plasmid 20, 171-174.

Chan, W. C., Dodd, H. M., Horn, N. \& Maclean, K. (1996). Structure-activity relationships in the peptide antibiotic nisin: role of dehydroalanine 5. Appl Environ Microbiol 62, 2966-2969.

Delves-Broughton, J., Blackburn, P., Evans, R. J. \& Hugenholtz, J. (1996). Applications of the bacteriocin, nisin. Antonie Leeuwenhoek 69, 193-202.

Engelke, G., Gutowski-Eckel, Z., Kiesau, P., Siegers, K., Hammelmann, M. \& Entian, K.-D. (1994). Regulation of nisin biosynthesis and immunity in Lactococcus lactis 6F3. Appl Environ Microbiol 60, 814-825.

Gasson, M. J. (1983). Plasmid complements of Streptococcus lactis NCDO 712 and other lactic streptococci after protoplastinduced curing. J Bacteriol 154, 1-9.

Graeffe, T., Rintala, H., Paulin, L. \& Saris, P. E. J. (1991). A natural nisin variant. In Nisin and Novel Lantibiotics, pp. 260-268. Edited by G. Jung \& H.-G. Sahl. Leiden: ESCOM Science Publishers.

Hanahan, D. (1983). Studies on transformation of Escherichia coli with plasmids. J Mol Biol 166, 557-580.

Holo, H. \& Nes, I. F. (1989). High-frequency transformation, by electroporation, of Lactococcus lactis subsp. cremoris grown with glycine in osmotically stabilized media. Appl Environ Microbiol 55, 3119-3123.

Immonen, T. \& Saris, P. E. J. (1998). Characterization of the nisFEG operon of the nisin $\mathrm{Z}$ producing Lactococcus lactis subsp. lactis N8 strain. DNA Seq 9, 263-274.

Immonen, T., Ye, S., Ra, R., Qiao, M., Paulin, L. \& Saris, P. E. J.
(1995). The codon usage of the nis $Z$ operon in Lactococcus lactis $\mathrm{N} 8$ suggests a non-lactococcal origin of the conjugative nisinsucrose transposon. DNA Seq 5, 203-218.

Jacobs, M. F., Tynkkynen, S. \& Sibakov, M. (1995). Highly bioluminescent Streptococcus thermophilus strain for the detection of dairy-relevant antibiotics in milk. Appl Environ Microbiol 44, 405-412.

Kalkkinen, N. \& Tilgman, C. (1988). A gas-pulsed liquid-phase sequencer constructed from a Beckman 890D instrument by using Applied Biosystems delivery and cartridge blocks. J Protein Chem 7, 242-243.

Kuipers, O. P., Beerthuyzen, M. M., Siezen, R. J. \& de Vos, W. M. (1993). Characterization of the nisin gene cluster nis ABTCIPR of Lactococcus lactis. Requirement of expression of the nis $A$ and nisI genes for development of immunity. Eur J Biochem 216, 281-291.

Kuipers, O. P., Beerthuyzen, M. M., de Ruyter, P. G. G. A., Luesink, E. J. \& de Vos, W. M. (1995). Autoregulation of nisin biosynthesis in Lactococcus lactis by signal transduction. J Biol Chem 270, 27299-27304.

Kupke, T. \& Götz, F. (1996). Posttranslational modifications of lantibiotics. Antonie Leeuwenhoek 69, 139-150.

Liu, W. \& Hansen, J. N. (1993). The antimicrobial effect of a structural variant of subtilin against outgrowing Bacillus cereus $\mathrm{T}$ spores and vegetative cells occurs by different mechanisms. Appl Environ Microbiol 59, 648-651.

Maniatis, T., Fritsch, E. F. \& Sambrook, J. (1982). Molecular Cloning: a Laboratory Manual. Cold Spring Harbor, NY: Cold Spring Harbor Laboratory.

Marmur, J. (1961). A procedure for the isolation of deoxyribonucleic acids from micro-organisms. J Mol Biol 3, 208-218.

McAuliffe, O., Ross, R. P. \& Hill, C. (2001). Lantibiotics: structure, biosynthesis and mode of action. FEMS Microbiol Rev 25, 285-308.

Meyer, C., Bierbaum, G., Heidrich, C., Reis, M., Suling, J., IglesiasWind, M. I., Kempter, C., Molitor, E. \& Sahl, H.-G. (1995). Nucleotide sequence of the lantibiotic Pep5 biosynthetic gene cluster and functional analysis of PepB and PepC. Eur J Biochem 232, 478-489.

Mulders, J. W., Boerrighter, I. J., Rollema, H. S., Siezen, R. J. \& de Vos, W. M. (1991). Identification and characterization of the lantibiotic nisin Z, a natural nisin variant. Eur J Biochem 201, 581-584.

Nes, I. F., Diep, D. B., Havarstein, L. S., Brurberg, M. B., Eijsink, V. \& Holo, H. (1996). Biosynthesis of bacteriocins in lactic acid bacteria. Antonie Leeuwenhoek 70, 113-128.

Qiao, M. \& Saris, P. E. J. (1996). Evidence for a role of NisT in transport of the lantibiotic nisin produced by Lactococcus lactis N8. FEMS Microbiol Lett 144, 89-93.

Qiao, M., Immonen, T., Koponen, O. \& Saris, P. E. J. (1995). The cellular location and effect on nisin immunity of the NisI protein from Lactococcus lactis N8 expressed in Escherichia coli and L. lactis. FEMS Microbiol Lett 131, 75-80.

Qiao, M., Ye, S., Koponen, O., Ra, R., Immonen, T. \& Saris, P. E. J. (1996). Regulation of the nisin operons in Lactococcus lactis N8. J Appl Bacteriol 80, 626-634.

Ra, R., Qiao, M., Immonen, T., Pujana, I. \& Saris, P. E. J. (1996). Genes responsible for nisin synthesis and immunity form a regulon of two operons and are induced by nisin in Lactococcus lactis N8. Microbiology 142, 1281-1288.

Ra, R., Beerthuyzen, M. M., de Vos, W. M., Saris, P. E. J. \& Kuipers, O.P. (1999). Differential contributions of NisI and 
NisFEG to producer-immunity analysed by in-frame disruptions in the nisin gene cluster of Lactococcus lactis. Microbiology 145, 1227-1233.

Saarinen, J., Welgus, H. G., Flizar, C. A., Kalkkinen, N. \& Helin, J. (1999). N-glycan structures of matrix metalloproteinase-1 derived from human fibroblasts and from HT-1080 fibrosarcoma cells. Eur J Biochem 259, 829-840.

Sahl, H.-G., Jack, R. W. \& Bierbaum, G. (1995). Biosynthesis and biological activities of lantibiotics with unique post-translational modifications. Eur J Biochem 230, 827-853.

Sen, A. K., Narbad, A., Horn, N., Dodd, H. M., Parr, A. J., Colquhoun, I. \& Gasson, M. J. (1999). Post-translational modification of nisin: the involvement of $\mathrm{NisB}$ in the dehydration process. Eur J Biochem 261, 524-532.

Siegers, K., Heinzman, S. \& Entian, K.-D. (1996). Biosynthesis of lantibiotic nisin - posttranslational modification of its prepeptide occurs at a multimeric membrane-associated lanthionine synthetase complex. J Biol Chem 271, 12294-12301.

Terzaghi, B. E. \& Sandine, W. E. (1975). Improved medium for lactic streptococci and their bacteriophages. Appl Microbiol 29, 807-813.

van der Meer, J. R., Polman., J., Beerthuyzen, M. M., Siezen, R. J., Kuipers, O. P. \& de Vos, W. M. (1993). Characterization of the Lactococcus lactis nisin A operon genes nisP encoding a subtilisinlike serine protease involved in precursor processing, and nisR, encoding a regulatory protein involved in nisin biosynthesis. J Bacteriol 175, 2578-2588.

Vieira, J. \& Messing, J. (1991). New pUC-derived cloning vectors with different selectable markers and DNA replication origins. Gene 100, 189-194.

Received 14 February 2002; revised 5 July 2002; accepted 15 July 2002. 